\title{
Faktor-Faktor Yang Mempengaruhi Produktivitas Tenaga Kerja PTPN X (PERSERO) Kebun Kertosari Jember
}

\author{
Dwi Cahyo Hermawan ${ }^{1 *}$, Wenny Dhamayanthi ${ }^{1}$, Ratih Puspitorini Yekti Ambarkahi ${ }^{1}$ \\ ${ }^{1}$ Department of Agribusiness Management, Politeknik Negeri Jember \\ *dwicahyohermawan12@gmail.com
}

Submitted: 12 Feb 2021

Accepted: 04 May 2021

Published: 28 Jun 2021

\begin{abstract}
ABSTRAK
Penelitian ini dilatarbelakangi karena Indonesia merupakan salah satu negara penghasil tembakau terbesar keenam didunia, dimana terdapat beberapa kota yang terkenal dengan produksi tembakaunya yaitu seperti di Jember.Di jember terdapat beberapa gudang tempat pengolahan tembakau diantaranya terdapat di PTPN X (PERSERO) Kebun Kertosari Jember.Pada penelitian ini bertujuan untuk mengetahui pengaruh motivasi, kompensasi dan lingkungan kerja terhadap produktivitas tenaga kerja bagian sortasi di PTPN X (PERSERO) Kebun Kertosari Jember. Metode yang digunakan yaitu observasi, kuisioner, wawancara dan studi literatur. Jumlah responden yang dijadikan sampel yaitu sebanyak 98 orang. Teknik analisis yang digunakan yaitu uji validitas dan reliabilitas, uji asumsi klasik, regresi linier berganda, analisis determinasi, uji F dan uji $\mathrm{t}$ dengan menggunakan alat analisis SPSS 22.0 for windows. Hasil pengujian diketahui bahwa (1) variabel motivasi (X1), kompensasi (X2) dan lingkungan kerja (X3) secara serempak berpengaruh signifikan terhadap produktivitas (Y). (2) variabel motivasi (X1), kompensasi (X2) dan lingkungan kerja (X3) secara parsial berpengaruh signifikan terhadap produktivitas (Y). (3) Variabel yang berpengaruh dominan terhadap produktivitas tenaga kerja (Y) di PTPN X (PERSERO) Kebun Kertosari Jember adalah variabel lingkungan kerja (X3).
\end{abstract}

Kata kunci: Motivasi, Kompensasi, Lingkungan Kerja, Produktivitas

\begin{abstract}
This research is motivated because Indonesia is one of the sixth largest tobacco producing countries in the world, where there are several cities that are famous for their tobacco production, such as in Jember. In Jember there are several warehouses where tobacco processing is located, including at PTPNX (PERSERO) Kebun Kertosari Jember. This study aims to determine the effect of motivation, compensation and work environment on labor productivity in the sorting department at PTPN X (PERSERO) Kebun Kertosari Jember. The methods used are observation, questionnaires, interviews and literature studies. The number of respondents who were sampled was 98 people. The analysis technique used is the validity and reliability test, classical assumption test, multiple linear regression, determination analysis, $F$ test and test using the SPSS 22.0 for windows analysis tool. The test results show that (1) the motivation variable (X1), compensation (X2) and the work environment (X3) simultaneously have a significant effect on productivity (Y). (2) the variables of motivation (X1), compensation (X2) and work environment (X3) partially have a significant effect on productivity (Y). (3) The variable that has the most dominant influence on labor productivity (Y) at PTPN X (PERSERO) Kebun Kertosari Jember is the work environment variable (X3).
\end{abstract}

Keyword: Motivation, Compensation, Work Environment, Productivity

\section{Pendahuluan}

Indonesia merupakan negara penghasil tembakau terbesar keenam setelah Cina, Brazil, India, USA dan Malawi dengan jumlah produksi sebesar 136.000 ton atau sekitar $1,91 \%$ dari total produksi tembakau dunia.
Produksi tembakau nasional di Indonesia berdasarkan data Direktorat Jendral Perkebunanan Kementrian Pertanian pada tahun 2020 mencapai 195.482 ton. Kondisi ini naik cukup signifikan yaitu $14,340 \%$ dari tahun sebelumnya seberat 181.142 ton. Kondisi tembakau dalam hal produksi dari setiap 
tahunnya selalu mengalami kenaikan yang cukup signifikan. Di Indonesia sebagian besar terdapat kota yang terkenal dengan produksi tembakaunya, salah satunya adalah di Kabupaten Jember.. Kabupaten Jember merupakan sebuah kota yang terkenal dengan perkebunan tembakau. Tempat pengolahan tembakau secara berkelanjutan dinamakan gudang. Gudang proses pengolahan lanjutan berjumlah cukup banyak di wilayah Kabupaten Jember.

PTPN X (PERSERO) Kebun Kertosari merupakan te mpat pengolahan tembakau yang terletak di Desa Kertosari Kecamatan Pakusari Kabupaten Jember. PTPN X (PERSERO) Kebun Kertosari memiliki jumlah tenaga kerja yang cukup banyak dalam proses produksinya, salah satunya terdapat dibagian sortasi. Pada bagian sortasi tembakau telah dilakukan secara benar dan telah sesuai dengan aturan dalam pengerjaannya. Namun masih tidak menunjukkan hasil akhir yang stabil dan perkembangan produktivitas tenaga kerja yang meningkat.

Berdasarkan hasil produksi selama beberapa tahun terakhir di PTPN X (PERSERO) Kebun Kertosari, masih terjadi naik turunnya hasil produksi tembakau. Hal tersebut terlihat dari target hasil produksi tembakau yang harusnya mencapai $100 \%$ namun sering terjadi penurunan bahkan terjadi ketidak stabilan dalam pencapaian hasil produksi. Naik turunnya hasil produksi tembakau dapat disebabkan oleh produktivitas tenaga kerjanya. Dimana di PTPN X (PERSERO) Kebun Kertosari dalam proses produksinya menggunakan lebih banyak tenaga manusia dibanding tenaga mesin. Sehingga hasil produksi tembakau sangat bergantung pada produktivitas tenaga kerja di suatu bagian.

Pada tenaga kerja bagian sortasi di PTPN X (PERSERO) Kebun Kertosari Jember telah dilakukan beberapa cara untuk meningkatkan produktivitas tenaga kerja, seperti halnya pemberian motivasi dari pihak petugas kontrol sortasi kepada tenaga kerja agar dapat menyortasi tembakau dengan cara yang benar sehingga mendapatkan kualitas tembakau sesuai standart perusahaan. Selain itu dengan pemberian kompensasi berupa upah serta jaminan kesehatan, pemberian fasilitas lingkungan kerja berupa tempat duduk dan meja telah perusahaan lakukan untuk meningkatkan produktivitas tenaga kerja bagian sortasi. Namun belum bisa memberikan peningkatan terhadap produktivitas tenaga kerja

Pengukuran terhadap produktivitas tenaga kerja kerja memiliki peranan sangat penting yang dapat meningkatkan produktivitas sesuai dengan harapan perusahaan. Perusahaan selalu berkeinginan agar tenaga kerja yang dimiliki mampu meningkatkan dan menghasilkan produktivitas yang tinggi. Menurut Kusrianto (1990) dalam Sutrisno (2009:102) produktivitas merupakan perbandingan antara hasil yang dicapai dengan peran serta tenaga kerja per satuan waktu. Sedangkan menurut Sutrisno (2009:103) produktivitas sangat dipengaruhi oleh faktor-faktor seperti pelatihan, mental dan kemampuan fisik karyawan serta hubungan antara atasan dan bawahan.

Motivasi adalah dorongan dasar yang menggerakkan seseorang atau keinginan untuk mencurahkan segala tenaga karena adanya suatu tujuan. Motivasi merupakan suatu faktor yang mendorong seseorang untuk melakukan suatu aktivitas tertentu (Gitasudarmo dalam Sutrisno, 2009 :109). Sedangkan menurut Priyono dan Marnis (2008:265) motivasi kerja didefinisikan sebagai dorongan, yang berarti tenaga yang menggerakkanjiwa dan jasmani untuk berbuat dan bertingkah laku dalam mencapai tujuan yang telah ditetapkan. Selain motivasi faktor penting yang mempengaruhi produktivitas tenaga kerja adalah kompensasi dan lingkungan kerja.

Menurut Hasibuan (2006 : 118), kompensasi adalah semua pendapatan yang berbentuk uang, barang langsung atau tidak langsung yang diterima karyawan sebagai imbalan atas jasa yang telah diberikan kepada perusahaan. Pemberian kompensasi kepada tenaga kerja sebagai bentuk balas jasa dan imbalan yang layak serta adil juga sebagai bentuk motivasi mereka dalam mencapai tujuan dari perusahaan. Selain itu faktor yang berpengaruh terhadap produktivitas tenaga kerja adalah lingkungan kerja. Lingkungan kerja merupakan kumpulan dari faktor yang bersifat fisik maupun non fisik, dimana keduanya mempengaruhi cara karyawan bekerja. Lingkungan kerja dapat berupa keadaan dimana tempat bekerja dan juga orang atau 
peralatan yang berada di lingkungan tempat kerja.

\section{Metode Penelitian}

Penelitian ini menggunakan pendekatan kauntitatif dengan pendekatan survei sebagai rancangan penelitian dengan cara menyebarkan kuisioner kepada responden atau sampel yang dipilih dengan menggunakan skala likert sebagai skala pengukuran. Populasi dalam penelian ini adalah tenaga kerja bagian sortasi tahap 1 yang berjumlah 130 orang di PTPN X (PERSERO) Kebun Kertosari Jember.

Teknik pengambilan sampel untuk penelitian ini yaitu menggunakan teknik simple random sampling yaitu pengambilan anggota sampel dari populasi yang dilakukan secara acak tanpa memperhatikan strata yang ada dalam populasi tersebut (Sugiyono, 2016:82) dengan menggunakan rumus slovin sehingga didapat besar sampel sejumlah 98 orang tenaga kerja bagian sortasi tahap 1 .

Metode analisis yang digunakan dalam penelitian ini adalah sebagai berikut :

\subsection{Uji Validitas dan Reliabilitas}

Singarimbun (1987:122) dalam Asnawai dan Masyhuri (2009:169) menjelaskan bahwa uji validitas menunjukan sejauh mana suatu alat pengukur itu mengukur apa yamg diukur. Menurut Asnawi dan Masyhuri (2009:169) rumus yang bisa digunakan untuk menguji validitas adalah sebagai berikut :

$$
r=\frac{N\left(\sum X Y\right)-\left(\sum X \sum Y\right)}{\sqrt{\left[N \Sigma X 2-\left(\sum X\right) 2\right]\left[N \sum Y 2-\left(\sum Y\right) 2\right]}}
$$

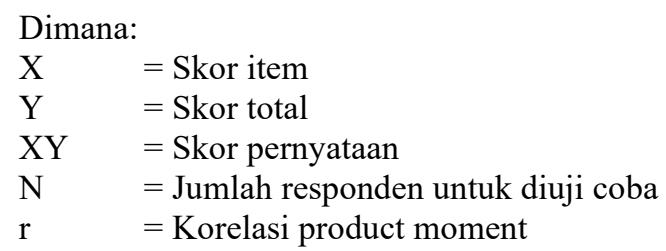

Menurut Asnawi dan Masyhuri (2009:171) reliabilitas adalah ukuran yang menunjukkan sejauh mana suatu alat ukur dapat dipercaya atau dapat diandalkan. Untuk mengetahui suatu alat ukur itu reliabel dapat diuji dengan menggunakan rumus Alpha sebagai berikut : $\mathrm{r}_{11}=\left(\frac{k}{k-1}\right)\left(1-\frac{\sum \sigma b 2}{\sigma 1^{2}}\right)$

Dimana :

$\begin{array}{ll}\mathrm{r}_{11} & =\text { Reliabilitas instrumen } \\ \mathrm{k} & =\text { Banyaknya butir pertanyaan } \\ \sum \sigma \mathrm{b}^{2} & =\text { Jumlah varians butir } \\ \sigma_{1}{ }^{2} & =\text { Varians total }\end{array}$

\subsection{Uji Asumsi Klasik}

\subsubsection{Uji Normalitas}

Pelaksanaan uji normalitas dapat menggunakan uji Kolmogrov-Smirnov, dengan kriteria yang berlaku yaitu apabila hasil signifikansi $>0,05$ berarti residual berdistribusi normal. (Sugiyono dan Susanto, 2017:323)

\subsubsection{Uji Multikolinieritas}

Kriteria pengujian dalam uji multikolinieritas adalah jika VIF yang dihasilkan diantara 1-10 maka tidak terjadi multikolinieritas.

\subsubsection{Uji Heteroskedastisitas}

Uji heteroskedastisitas dapat dilakukan menggunakan uji Glejser yang mana jika nilai signifikan lebih besar dari 0,05 maka dapat disimpulkan model regresi tidak terdapat adanya heteroskedastisitas.

\subsubsection{Analisis Regresi Linier Berganda}

Menurut Santosa dan Ashari (2005:144) dalam Asnawi dan Masyhuri (2009:181) regresi linier bergamda merupakan persamaan dengan menggunakan dua atau lebih variabel independen. Bentuk persaamaan regresi linier berganda adalah sebagai berikut :

$\mathrm{Y}=\mathrm{a}+\mathrm{b}_{1} \mathrm{X}_{1}+\mathrm{b}_{2} \mathrm{X}_{2}+\ldots . .+\mathrm{b}_{\mathrm{n}} \mathrm{X}_{\mathrm{n}}+\mathrm{e}$

\footnotetext{
Dimana :

$\mathrm{Y}=$ Variabel tak bebas atau terikat

a $=$ Koefisien Konstanta

$\mathrm{b}=$ Konstanta perubahan variabel $\mathrm{X}$ terhadap $\mathrm{Y}$

$\mathrm{n}=$ Jumlah variabel

$\mathrm{X}=$ Variabel bebas

e $=$ Error (tingkat kesalahan)
} 


\subsubsection{Analisis Koefisien Determinasi (Adjusted $R^{2)}$}

Adapun rumus adjusted $R$ square yang biasa digunakan adalah :

$$
\text { Adjusted } R^{2}=1-\left(1-\mathrm{R}^{2}\right)\left[\frac{n-1}{n-k}\right]
$$

$$
\begin{aligned}
& \text { Keterangan: } \\
& \mathrm{R}^{2} \quad=\text { Koefisien determinasi } \\
& \mathrm{n}=\text { Jumlah responden } \\
& \mathrm{k}=\text { Jumlah variabel bebas }
\end{aligned}
$$

\subsubsection{Uji $F$}

Uji $F$ atau disebut juga korelasi ganda digunakan untuk menguji pengaruh variabel bebas secara bersama-sama terhadap variabel terikat (Asnawi dan Masyhuri, 2009:182). Adapaun rumus yang digunakan adalah sebagai berikut :

$$
\mathrm{F}=\frac{\mathrm{R}^{2} / \mathrm{K}}{\left(1-\mathrm{R}^{2}\right) /(\mathrm{n}-\mathrm{K}-1)}
$$

\section{Dimana:}

$$
\begin{array}{ll}
\mathrm{F} & =\text { Pendekatan distribusi probabilitas fischer } \\
\mathrm{R}^{2} & =\text { Koefisien korelasi berganda } \\
\mathrm{K} & =\text { Jumlah variabel bebas } \\
\mathrm{n} & =\text { Banyaknya sampel }
\end{array}
$$

\subsubsection{Uji $t$}

Menurut Asnawi dan Masyhuri (2009:182) uji t digunakan untuk membuktikan signifikan atau tidaknya pengaruh variabel bebas terhadap variabel tak bebas secara individual (parsial). Adapaun rumus uji t adalah sebagai berikut :

$t=r=\left\{\frac{\mathrm{n}-2}{1-1^{2}}\right\} 1 / 2$

Dimana:

$\mathrm{r}=$ Korelasi produk momen

$\mathrm{n}=$ Jumlah responden

\section{Hasil dan Pembahasan}

\subsection{Hasil Uji Validitas}

Berdasarkan kriteria uji validitas apabila nilai signifikansi lebih kecil daripada tingkat kesalahan yaitu 0,05 maka seluruh instrumen tersebut telah memenuhi kriteria validitas sehinga setiap butir pernyataan dari setiap variabel yaitu motivasi, kompensasi, lingkungan kerja dan produktivitas valid dan layak digunakan.

Table 1. Hasil Uji Validitas

\begin{tabular}{ccccc}
\hline Variabel & $\begin{array}{c}\text { Item } \\
\text { Pertanyaan }\end{array}$ & $\begin{array}{c}\mathrm{r} \\
\text { hitung }\end{array}$ & $\begin{array}{c}\text { Signifikansi } \\
(\alpha=0,05)\end{array}$ & Keterangan \\
\hline Motivasi & $\mathrm{X} 1.1$ & 0,811 & 0,000 & Valid \\
(X1) & $\mathrm{X} 1.2$ & 0,802 & 0,000 & Valid \\
& $\mathrm{X} 1.3$ & 0,780 & 0,000 & Valid \\
Kompensasi & $\mathrm{X} 2.1$ & 0,788 & 0,000 & Valid \\
(X2) & $\mathrm{X} 2.2$ & 0,815 & 0,000 & Valid \\
& $\mathrm{X} 2.3$ & 0,689 & 0,000 & Valid \\
Lingkungan & $\mathrm{X} 3.1$ & 0,902 & 0,000 & Valid \\
Kerja (X3) & $\mathrm{X} 3.2$ & 0.899 & 0,000 & Valid \\
& $\mathrm{X} 3.3$ & 0,887 & 0,000 & Valid \\
Produktivitas & $\mathrm{Y} 1.1$ & 0,812 & 0,000 & Valid \\
(Y) & $\mathrm{Y} 1.2$ & 0,834 & 0,000 & Valid \\
& $\mathrm{Y} 1.3$ & 0,793 & 0,000 & Valid \\
\hline
\end{tabular}

3.2. Hasil Uji Reliabilitas

Table 2. Hasil Uji Reliabilitas

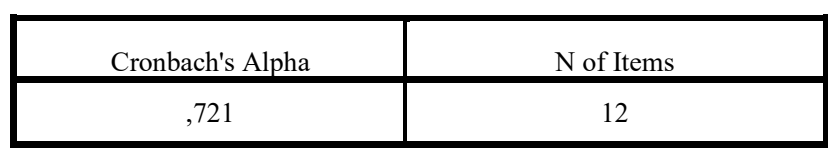

Dapat diketahui bahwa nilai Cronbach Alpha sebesar 0,721 dan nilai tersebut lebih besar dari 0,60 yang berarti bahwa seluruh butir pernyataan dalam kuisioner dapat dikatakan bersifat reliabel.

\subsection{Hasil Uji Asumsi Klasik}

\subsubsection{Uji Normalitas}

a. Analisis Grafik

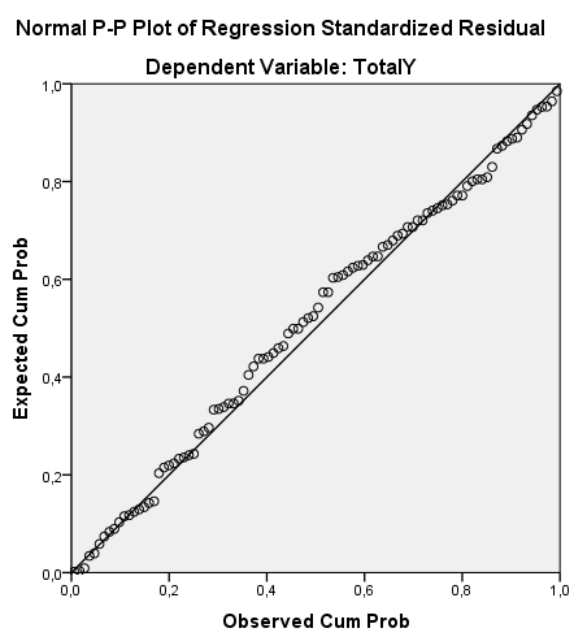

Dapat diketahui bahwa data yang berupa titik-titik pada variabel motivasi (X1), kompensasi (X2), lingkungan kerja (X3), dan produktivitas (Y) menyebar disekitar garis diagonal dan mengikuti arah dari garis 
diagonalnya, maka dapat disimpulkan bahwa data tersebut berdsitribusi normal.

\section{b. Uji Kolmogrov-Smirnov}

Table 3. Hasil Uji Kolmogorv-Smirnov

\begin{tabular}{|ll|r|}
\hline & & Unstandardized Residual \\
\hline $\mathrm{N}$ & Mean & 98 \\
Normal & Std. &, 0000000 \\
Parameters & \\
& Deviation & 1,51994366 \\
Most Extreme & Absolute &, 074 \\
Differences & Positive &, 045 \\
& Negative &,- 074 \\
Test Statistic & &, 074 \\
Asymp. Sig. (2-tailed) &, 200 \\
\hline
\end{tabular}

a. Test distribution is Normal.

b. Calculated from data.

Dapat diketahui bahwa hasil dari uji normalitas menggunakan Kolmogrov-Smirnov diperoleh nilai signifikansi (Asymp sig 2-tailed) adalah sebesar 0,200 dimana nilai signifikansi tersbebut lebih besar dari 0,05. Dapat disimpulkan bahwa data terebut berdistribusi normal karena nilai signifikansi lebih besar dari 0,05 .

\subsubsection{Uji Multikolinieritas}

Table 4. Hasil Uji Multikolinieritas

\begin{tabular}{lcc}
\hline \multicolumn{1}{c}{$\begin{array}{c}\text { Variabel } \\
\text { Independen }\end{array}$} & VIF & Kesimpulan \\
\hline Motivasi (X1) & 1,147 & Tidak Terjadi Multikolinieritas \\
Kompensasi (X2) & 1,088 & Tidak Terjadi Multikolinieritas \\
$\begin{array}{l}\text { Lingkungan Kerja } \\
(\mathrm{X} 3)\end{array}$ & 1,092 & Tidak Terjadi Multikolinieritas \\
\hline
\end{tabular}

Dapat diketahui bahwa nilai VIF yang dihasilkan antar variabel baik variabel motivasi (X1), kompensasi (X2), dan lingkungan kerja (X3) berada diantara 1-10. Dapat disimpulkan bahwa tidak terjadi gelaja mutikolinieritas antar variabel independen.

\subsubsection{Uji Heteroskedastisitas}

a. Uji Scatterplot

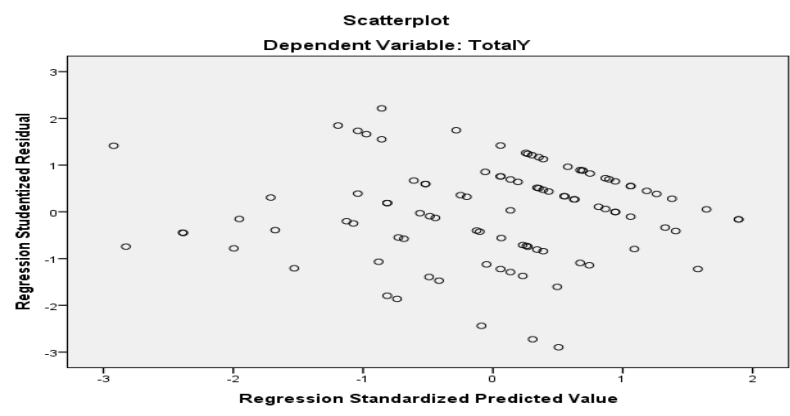

Dapat terlihat bahwa titik-titik menyebar secara acak dan tidak membentuk sebuah pola tertentu serta terletak diatas dan dibawah angka 0 pada sumbu Y, hal ini menunjukkan bahwa tidak adamya gejala heteroskedastisitas pada residual data.

\section{b. Uji Glejser}

Table 5. Hasil Uji Glejser

\begin{tabular}{lcc}
\hline \multicolumn{1}{c}{$\begin{array}{c}\text { Variabel } \\
\text { Independen }\end{array}$} & Signifikansi & Kesimpulan \\
\hline Motivasi (X1) & 0,064 & $\begin{array}{c}\text { Tidak Terjadi } \\
\text { Heteroskedastisitas } \\
\text { Tidak Terjadi } \\
\text { Kompensasi (X2) }\end{array}$ \\
$\begin{array}{l}\text { Heteroskedastisitas } \\
\text { Lingkungan Kerja }\end{array}$ & 0,381 & Tidak Terjadi \\
(X3) & & Heteroskedastisitas \\
\hline
\end{tabular}

Dapat diketahui bahwa seluruh variabel memiliki nilai signifikansi lebih dari 0,05 sehingga dapat disimpulkan tidak terjadi heteroskedastisitas pada residual data tersebut.

\section{c. Analisis Regresi Linier Berganda}

Table 6. Hasil Analisis Regresi Linier Berganda

\begin{tabular}{|l|c|c|l|l|l|}
\hline \multirow{2}{*}{ Model } & \multicolumn{2}{|c|}{$\begin{array}{c}\text { Unstndarized } \\
\text { Coeffisients }\end{array}$} & $\begin{array}{l}\text { Standardized } \\
\text { Coefficients }\end{array}$ & \multirow{2}{*}{$\mathrm{t}$} & sig \\
\cline { 2 - 5 } & $\mathrm{B}$ & $\begin{array}{c}\text { Std. } \\
\text { Error }\end{array}$ & \multicolumn{1}{|c|}{ Beta } & & \\
\hline 1 (Constant) & 7,552 & 1,633 & & 4,623 &, 000 \\
\hline $\begin{array}{l}\text { Motivasi } \\
\text { (X1) }\end{array}$ &,- 415 &, 094 &,- 369 & $-4,398$ &, 000 \\
\hline $\begin{array}{l}\text { Kompensasi } \\
\text { (X2) }\end{array}$ &, 254 &, 098 &, 212 & 2,601 &, 011 \\
\hline $\begin{array}{l}\text { Lingkungan } \\
\text { Kerja (X3) }\end{array}$ &, 569 &, 072 &, 651 & 7,956 &, 000 \\
\hline
\end{tabular}


Berdasarkan hasil perhitungan menggunakan SPSS 22.0 for Windows yang ditunjukkan pada tabel 4.9 diatas, maka persamaan regresi linear berganda adalah sebagai berikut :

$Y=7,552-0,415 X 1+0,254 X 2+0,569 X 3+e$

Berikut merupakan penjelasan berdasarkan persamaan regresi linear berganda diatas :

- Nilai konstanta (a)

Nilai konstanta memiliki nilai positif sebesar 7,552 menunjukkan bahwa apabila tidak ada variabel Motivasi (X1), Kompensasi (X2), dan Lingkungan Kerja (X3) maka Produktivitas sebesar 7,552.

\section{- Nilai koefisien Motivasi (X1)}

Nilai koefisien Motivasi (X1) memiliki nilai negatif sebesar 0,415 menunjukkan bahwa setiap peningkatan motivasi sebesar satu satuan maka produktivitas tenaga kerja bagian sortasi PTPN X Kebun Kertosari Jember juga akan menurun sebesar 0,415.

- Nilai koefisien Kompensasi (X2)

Nilai koefisien Kompensasi (X2) memiliki nilai positif sebesar 0,254 menunjukkan bahwa setiap peningkatan kompenasi sebesar satu satuan maka produktivitas tenaga kerja bagian sortasi PTPN X Kebun Kertoasari Jember juga akan meningkat sebesar 0,254.

- Nilai koefisien Lingkungan Kerja (X3)

Nilai koefisien Lingkungan Kerja (X3) memiliki nilai positif sebesar 0,569 menunjukkan bahwa setiap peningkatan lingkungan kerja sebesar satu satuan maka produktivitas tenaga kerja bagian sortasi PTPN X Kebun Kertosari Jember juga akan meningkat sebesar 0,569.

\section{d. Hasil Analisis Koefisien Determinasi (Adjusted $\mathrm{R}^{2}$ )}

Table 7. Hasil Analisis Koefisien Determinasi (Adjusted $\left.R^{2}\right)$

\begin{tabular}{|l|c|r|r|r|r|}
\hline Model & $\mathrm{R}$ & $\begin{array}{c}\mathrm{R} \\
\text { Square }\end{array}$ & $\begin{array}{c}\text { Adjusted R } \\
\text { Square }\end{array}$ & $\begin{array}{c}\text { Std. Error of } \\
\text { the Estimate }\end{array}$ & $\begin{array}{c}\text { Durbin- } \\
\text { Watson }\end{array}$ \\
\hline 1 &, $651^{\mathrm{a}}$ &, 424 &, 406 & 1,544 & 1,645 \\
\hline
\end{tabular}

Dapat diketahui bahwa hasil analisis koefisien determinasi (Adjuested $R^{2}$ ) memiliki nilai 0,406 atau 40,6\%. Hal ini menunjukkan bahwa variabel bebas (independen) yaitu motivasi (X1), kompensasi (X2), dan lingkungan kerja (X3) memberikan pengaruh terhadap variabel terikat (dependen) yaitu produktivitas (Y) sebesar 40,6\% sedangkan sisanya yaitu $59,4 \%(100 \%-40,6 \%)$ dipengaruhi oleh variabel bebas lainnya yang tidak diteliti oleh peneliti seperti usia, disiplin kerja, seleksi dan lain-lain.

e. Hasil Uji F

Table 8. Hasil Uji F

\begin{tabular}{|c|c|c|c|c|c|}
\hline Model & $\begin{array}{l}\text { Sum of } \\
\text { Squares }\end{array}$ & Df & $\begin{array}{l}\text { Mean } \\
\text { Square }\end{array}$ & $\mathrm{F}$ & Sig. \\
\hline 1 Regression & 164,969 & 3 & 54,990 & 23,067 &, $000^{\mathrm{b}}$ \\
\hline Residual & 224,092 & 94 & 2,384 & & \\
\hline Total & 389,061 & 97 & & & \\
\hline
\end{tabular}

a. Dependent Variable: Produktivitas (Y)

b. Predictors: (Constant), Motivasi (X1), Kompensasi (X2), Lingkungan Kerja (X3)

Dapat diketahui bahwa nilai probabilitas yang diperoleh yaitu 0,000 dimana nilai tersebut lebih kecil dari taraf signifikansi yaitu 0,05 . Berdasarkan dasar pengambilan keputusan bahwasannya apabila nilai probabilitas $<$ taraf signifikansi yaitu 0,05 maka dapat disimpulakan hipotesis diterima, sehingga variabel bebas (independen) yaitu motivasi (X1), kompensasi (X2), dan lingkungan kerja (X3) secara bersamasama atau serempak berpengaruh signifikan terhadap variabel terikat (dependen) yaitu produktivitas tenaga kerja bagian sortasi pada PTPN X Kebun Kertosari Jember.

\section{f. Hasil Uji t}

Table 9. Hasil Uji t

\begin{tabular}{|l|c|c|c|c|c|}
\hline \multirow{2}{*}{ Model } & \multicolumn{2}{|c|}{$\begin{array}{c}\text { Unstndarized } \\
\text { Coeffisients }\end{array}$} & $\begin{array}{c}\text { Standardized } \\
\text { Coefficients }\end{array}$ & \multirow{2}{*}{$\mathrm{t}$} & sig \\
\cline { 2 - 5 } & $\mathrm{B}$ & $\begin{array}{c}\text { Std. } \\
\text { Error }\end{array}$ & Beta & & \\
\hline 1 (Constant) & 7,552 & 1,633 & & 4,623 &, 000 \\
\hline Motivasi (X1) &,- 415 &, 094 &,- 369 & $-4,398$ &, 000 \\
\hline $\begin{array}{l}\text { Kompensasi } \\
(X 2)\end{array}$ &, 254 &, 098 &, 212 & 2,601 &, 011 \\
\hline $\begin{array}{l}\text { Lingkungan } \\
\text { Kerja (X3) }\end{array}$ &, 569 &, 072 &, 651 & 7,956 &, 000 \\
\hline
\end{tabular}


Berdasarkan hasil Uji t pada tabel 4.12 diatas dapat dilihat hasil nilai signifikan sehingga dapat disimpulkan bahwa:

- Variabel Motivasi (X1) memiliki nilai signifikansi sebesar 0,000. Hal ini menunjukkan bahwa nilai signifikansi yaitu sebesar 0,000 lebih kecil daripada nilai tingkat kesalahan sebesar 0,05. Sehingga dapat disimpulkan bahwa variabel bebas yaitu motivasi (X1) berpengaruh signifikan terhadap variabel terikat yaitu produktivitas (Y) pada tenaga kerja bagian sortasi di PTPN X (PERSERO) Kebun Kertosari Jember.

- Variabel Kompensasi (X2) memiliki nilai signifikansi sebesar 0,011. Hal ini menunjukkan bahwa nilai signifikansi yaitu sebesar 0,011 lebih kecil daripada nilai tingkat kesalahan sebesar 0,05. Sehingga dapat disimpulkan bahwa variabel bebas yaitu kompenasi (X2) bepengaruh signifikan terhadap variabel terikat yaitu produktivitas (Y) pada tenaga kerja bagian sortasi di PTPN $X$ (PERSERO) Kebun Kertosari Jember.

- Variabel Lingkungan Kerja (X3) memiliki nilai signifikansi sebesar 0,000. Hal ini menunjukkan bahwa nilai signifikansi yaitu sebesar 0,000 lebih kecil daripada nilai tingkat kesalahan sebesar 0,05. Sehingga dapat disimpulkan bahwa variabel bebas yaitu lingkungan kerja (X3) berpengaruh signifikan terhadap variabel terikat yaitu produktivitas (Y) pada tenaga kerja bagian sortasi di PTPN $\mathrm{X}$ Kebun Kertosari Jember.

\section{Pembahasan}

4.1. Variabel Motivasi, Kompensasi dan Lingkungan Kerja berpengaruh secara serempak terhadap produktivitas tenaga kerja bagian sortasi di PTPN X (PERSERO) Kebun Kertosari Jember

Berdasarkan hasil penelitian dan hasil dari analisis data yang telah dilakukan, dapat diketahui bahwasannya terdapat bukti variabel bebas yaitu motivasi (X1), kompensasi (X2) dan lingkungan kerja (X3) memiliki pengaruh yang signifikan terhadap variabel terikat yaitu produktivitas tenaga kerja dengan hasil perolehan tingkat signifikansi sebesar 0,000 lebih kecil dari taraf signifikansi 0,05 maka dapat disimpulkan dan diketahui bahwa variabel bebas yaitu motivasi (X1), kompensasi (X2), dan lingkungan kerja (X3) berpengarh secara bersama-sama atau serempak terhadap variabel terikat yaitu produktivitas tenaga kerja (Y).

Hasil penelitian yang dilakukan terhadap tenaga kerja bagian sortasi juga menunjukkan bahwa dengan adanya motivasi yang timbul dari dalam diri tenaga kerja dan juga motivasi dari atasan serta dengan kompensasi dan lingkungan kerja yang disediakan oleh perusahaan maka akan meningkatkan produktivitas tenaga kerja bagian sortasi di PTPN X (PERSERO) Kebun Kertosari Jember. Dengan begitu variabel Motivasi (X1), Kompensasi (X2) dan Lingkungan Kerja (X3) berpengaruh secara serempak terhadap variabel Produktivitas (Y).

4.2. Variabel Motivasi, Kompensasi, dan Lingkungan Kerja berpengaruh secara parsial terhadap produktivitas tenaga kerja bagian sortasi di PTPN X (PERSERO) Kebun Kertosari Jember

\subsubsection{Pengaruh Variabel Motivasi (XI) Terhadap Produktivitas Tenaga Kerja Bagian Sortasi}

Hasil dari pengujian yang telah dilakukan menunjukkan bahwa variabel Motivasi (X1) mempunyai nilai signifikansi sebesar 0,000 lebih kecil dari 0,05. Hal ini menunjukkan bahwa variabel Motivasi (X1) berpengaruh secara signifikan terhadap Produktivitas Tenaga Kerja (Y) bagian sortasi di PTPN X (PERSERO) Kebun Kertosari Jember.

Berdasarkan hasil dari penilaian yang dilakukan oleh responden yiatu tenaga kerja bagian sortasi melalui kuisioner yang diberikan menunjukkan bahwa motivasi baik yang berasal dari dalam diri tenaga kerja dan dari luar tenaga kerja sama-sama dapat menjadi faktor pendorong bagi tenaga kerja untuk lebih semangat dalam melakukan pekerjaan mereka. Adanya motivasi dari dalam diri tenaga keja seperti menyadari akan kewajiban dan tanggung jawab dalam melaksanakan pekerjaan akan menjadikan semangat bagi mereka, selain itu adanya motivasi dari atasan atau pimpinan dan teman kerja juga dapat mendorong tenaga kerja agar lebih giat dan 
termotivasi untuk melakukan pekerjaan yaitu menyortasi tembakau agar dapat dihasilkan tembakau dengan kualitas terbaik sehingga produktivitas akan lebih meningkat bagi perusahaan.

\subsubsection{Pengaruh Variabel Kompensasi (X2) Terhadap Produktivitas Tenaga Kerja Bagian Sortasi}

Hasil dari pengujian yang telah dilakukan menunjukkan bahwa variabel Kompensasi (X2) mempunyai nilai signifikansi sebesar 0,011 lebih kecil dari 0,05. Hal ini menunjukkan bahwa variabel Kompensasi (X2) berpengaruh secara signifikan terhadap Produktivitas Tenaga Kerja (Y) bagian sortasi di PTPN X (PERSERO) Kebun Kertosari Jember.

Berdasarkan hasil dari penilaian yang dilakukan oleh responden yaitu tenaga kerja bagian sortasi melalui kuisioner yang diberikan menunjukkan bahwa kompensasi yang telah diberikan oleh perusahaan yang berupa upah, pemberian asuransi kesehatan dan promosi jabatan telah sesuai dengan harapan tenaga kerja bagian sortasi. Dengan adanya pemeberian kompensasi yang berupa upah, asuransi kesehatan berupa tunjangan kesehatan (JAMSOSTEK) dan promosi jabatan menandakan perusahaan telah peduli terhadap kesejahteraan tenaga kerjanya, hal ini juga akan membuat tenaga kerja akan semakin bersemangat untuk bekerja dan dapat meningkatkan produktivitas kerja mereka sehingga dapat menguntungkan bagi perusahaan.

\subsubsection{Pengaruh Variabel Lingkungan Kerja (X3) Terhadap Produktivitas Tenaga Kerja Bagian Sortasi}

Hasil dari pengujian yang telah dilakukan menunjukkan bahwa variabel Lingkungan Kerja (X3) mempunyai nilai signifikansi sebesar 0,000 lebih kecil dari 0,05. Hal ini menunjukkan bahwa variabel Lingkungan Kerja (X3) berpengaruh secara signifikan terhadap Produktivitas Tenaga Kerja (Y) bagian sortasi di PTPN X (PERSERO) Kebun Kertosari Jember.

Berdasarkan hasil dari penilaian yang dilakukan oleh responden yaitu tenaga kerja bagian sortasi melalui kuisioner yang diberikan menunjukkan bahwa lingkungan kerja yang berada di perusahan sudah dirasa cukup baik dalam mendukung proses sortasi temabakau yang dilakukan oleh tenaga kerja bagian sortasi. Adanya pencahayaan dan penerangan berupa lampu dapat sangat membantu tenaga kerja dalam melakukan proses sortasi tembakau agar tembakau yang dilakukan sortasi telah memenuhi standart yang telah ditetapkan oleh perusahaan dan merupakan tembakau yang memiliki kualitas terbaik. Selaian itu adanya ventilasi udara berupa jendela juga dapat berfungsi sebagai alat pertukuran udara dan menjaga suhu didalam ruangan sortasi, agar tenaga kerja merasa nyaman berada ditempat kerja. Dengan diperhatikannya dan disediakannya lingkungan kerja yang nyaman dan layak bagi tenaga kerja maka akan menyebabkan peningkatan produktivitas tenga akerja bagian sortasi di PTPN X (PERSERO) Kebun Kertosari Jember.

\subsection{Variabel yang Memiliki Pengaruh Dominan Terhadap Produktivitas Tenaga Kerja Bagian Sortasi}

Dari analisis yang telah dilakukan dapat diketahui dan disimpulkan bahwa variabel yang memiliki pengaruh dominan terhadap produktivitas tenaga kerja bagian sortasi adalah variabel Lingkungan Kerja (X3). Vaeriabel Lingkungan Kerja memiliki nilai thitung yaitu sebesar 7,956 dengan nilai signifikansi 0,000 lebih kecil dari 0,05 dan merupakan variabel yang memiliki nilai thitung terbesar jika dibandingkan dengan variabel lainnya seperti Motivasi (X1) dan Kompensasi (X2). Hal ini membuktikan bahwa variabel Lingkungan Kerja memiliki pengaruh dominan terhadap Produktivitas Tenaga Kerja (Y).

Maka dapat diketahui bahwa lingkungan kerja yang telah perusahaan berikan dan sediakan sudah mampu dan efektif dalam peningkatan produktivitas tenaga kerja dalam melakukan proses sortasi tembakau. Dikarenakan pada saat proses sortasi tembakau tenaga kerja membutuhkan pencahayaan dan penerangan yang cukup, serta perlu adanya ventilasi seperti jendela sebagai tempat pertukaran udara dan suhu dalam ruangan sortasi. 


\section{Kesimpulan}

Berdasarkan penelitian mengenai pengaruh Motivasi, Kompensasi dan Lingkungan Kerja Terhadap Produktivitas Tenaga Kerja Bagian Sortasi Di PTPN X (PERSERO) Kebun Kertosari Jember didapatkan kesimpulan bahwa berdasarkan pengujian serempak (Uji F) seluruh variabel secara serempak berpengaruh signifikan terhadap produktivitas tenaga kerja bagian sortasi, berdasarkan pengujian secara parsial (Uji t) seluruh variabel secara parsial berpengaruh signifikan terhadap produktivitas tenaga kerja bagian sortasi, dan variabel yang berpengaruh dominan terhadap produktivitas tenga kerja bagian sortasi adalah variabel lingkungan kerja (X3). Saran yang dapat diberikan kepada perusahaan adalah agar lebih memperhatikan dan lebih meningkatkan faktor lingkungan kerja bagi tenaga kerja agar dapat memberikan keuntungan bagi perusahaan. Sedangkan untuk penelitan selanjutnya diharapkan agar menambahkan beberapa variabel lain agar dapat memperluas literatur penelitian.

\section{Daftar Pustaka}

[1] Asnawi, N. dan Masyhuri. 2009. Metodologi Riset Manajemen Pemasaran. Cetakan ke 1. Malang : UINMalang Press.

[2] Hasibuan. 2006. Manajemen Sumber Daya Manusia, Edisi Revisi, Jakarta : Bumi Aksara.

[3] Priyono, \& Marnis. 2008 Manajemen Sumber Daya Manusia. Sidoarjo : Zifataama Publisher.

[4] Sugiyono. 2016. Metode Penelitian Kuantitatif, Kualitatif, dan R\&D. Cetakan ke-23. Bandiung : Alfabeta.

[5] Sugiyono, dan Susanto. 2017. Cara Mudah Belajar SPSS dan Lisrel (Teori dan Aplikasi Untuk Analisis Data Penelitian). Cetakan kesatu. Bandung : Alfabeta.

[6] Sutrisno, E. 2009. Manajemen Sumber Daya Manusia. Edisi Pertama. Jakarta : KENCANA. 